\title{
FORMULATION AND EVALUATION OF ACECLOFENAC PRONIOSOME LOADED ORABASE FOR MANAGEMENT OF DENTAL PAIN
}

\section{G. V. RADHA ${ }^{*}$, K. TRIDEVA SASTRI ${ }^{1}$, P. PRATHYUSHA ${ }^{1}$, P. BHANU ${ }^{1}$, JAMPALA RAJKUMAR1}

1GITAM Institute of Pharmacy, GITAM Deemed to be University, Rushikonda, Visakhapatnam, Andhra Pradesh State, India Email: radhagadela@gmail.com

Received: 16 Aug 2018, Revised and Accepted: 21 Sep 2018

\section{ABSTRACT}

Objective: The main motive is to develop proniosomes loaded orabase for enhanced permeation and prolonged release of aceclofenac for oro dental conditions.

Methods: Various aceclofenac (ACL) proniosomal gels were formulated employing various surfactants, span 60 was superior and significant for loading into orabase. The formulations were scrutinized for entrapment efficiency, optical microscopy, in vitro diffusion and release studies, mucoadhesive strength, ex-vivo permeation studies and drug-excipient interactions were determined by FTIR spectroscopy.

Results: Considering best entrapment efficiency with span $60(97.60 \pm 1.85)$ and optimum vesicle shape, along with prolonged drug permeation $(45 \%$ for $24 \mathrm{~h})$ the formulation F(ACL) 1 was selected and optimized for loading into orabase. The F(ACL)1 loaded orabase exhibited significant prolonged release over $14 \mathrm{~h}$, and permeation profiles exhibited nearly two-fold increased flux in comparison with control. Good mucoadhesive strength was observed for proniosomal orabase 6370 dynes $/ \mathrm{cm}^{2}$. No evidence of incompatibility amongst formulation components from FTIR studies. SEM images revealed the particle size range from $136 \mu \mathrm{m}$ to $236 \mu \mathrm{m}$ for proniosomal orabase.

Conclusion: Orabase can be an effective carrier for proniosomes with enhanced permeation and prolonged release for oro-dental conditions.

Keywords: Aceclofenac, Oro-dental pain, proniosomal gel, Orabase, Entrapment efficiency, Prolonged release

(C) 2018 The Authors. Published by Innovare Academic Sciences Pvt Ltd. This is an open access article under the CC BY license (http://creativecommons.org/licenses/by/4.0/) DOI: http://dx.doi.org/10.22159/ijap.2018v10i6.29143

\section{INTRODUCTION}

Patients with oro-dental aliments often suffer awful pain due to significant tissue damage and inflammation. The effective analgesic screening and dosage regimen depend on the nature and intensity of pain the patient experience. Oral cavities are the chief complaint about a toothache, nonsteroidal anti-inflammatory drugs (NSAIDs) effectively mitigate acute and chronic dental, tissues and other adjacent structures [1]. With the advancements in understanding, pain pathophysiology novel strategies for drug delivery assessed to alleviate pain at peripheral sites to enhance the therapeutic benefit of the drug [2].

ACL is an NSAID and exhibits potent analgesic activity, effective in the treatment of painful inflammatory conditions, mostly administered orally. It is broadly prescribed for conditions rheumatoid arthritis, osteoarthritis, acute lumbago, and dental pain and oral dental ailments. Gastrointestinal disturbances raise concerns to post oral ACL administration. Hence, a better strategy with a significant scale of safety is essential to overcome such systemic side-effects. One such strategy, designing the delivery system with localized action at the site of ailment. Thereby, lowers systemic disturbances and improves the efficiency of the drug by potentiating drug concentration at the site of inflammation with low dose relative to conventional oral administration hence increases patient compliance.

Proniosomes are dehydrated preparations employing suitable nonionic surfactants and carrier, the preparation further yields niosomes on hydration with water [3]. Niosomes are proven to be best carriers for drug targeting, relatively less toxic, stable, and economical and better permeation than liposomes.
Ora base is an effective mucoadhesive base effectively employed as a drug carrier, considered as a hydrophobic gel or dental paste. The aim of the present investigation was to achieve the prolonged release of ACL by loading in proniosome vesicles and improve its retention time at the particular site of action by incorporating drug loaded proniosomes into orabase this significantly reduces dosage frequency hence increase patient compliance.

\section{MATERIALS AND METHODS}

\section{Materials}

ACL was purchased from yarrow chem products (Mumbai, India), span 40 (sorbitan monopalmitate) and span 60 (sorbitan monostearate), were purchased from loba chemie pvt. Itd. (Mumbai, India), span 20 (sorbitan monolaurate) and span 80 (sorbitan monooleate) were purchased from molychem (Mumbai, India). Cholesterol was purchased from finar chemicals pvt. Ltd (Ahmedabad, India) and soya lecithin were obtained from sigma chemicals limited (Hyderabad, India).

\section{Methods}

\section{Preparation of aceclofenac proniosomal gel}

ACL loaded proniosomal gel was formulated employing coacervation phase separation method $[4,5]$. The required measures of surfactant, lecithin and c holesterol were dissolved in alcohol in a beaker as shown in (table 1). Contents were stirred uniformly using glass rod, further introduced into water bath shaker (REMI) to warm the ingredients $\left(60-70{ }^{\circ} \mathrm{C}\right)$ for about five minutes for complete solubilization. Consequently, aqueous buffer $\mathrm{pH} 7.4$ was added to the preparation, with gentle warming yielded proniosomal gel on cooling.

Table 1: Composition of the proniosomal formulation of Aceclofenac

\begin{tabular}{lllllll}
\hline S. No. & Formulation & Surfactant & $\begin{array}{l}\text { Drug } \\
\text { (mg) }\end{array}$ & $\begin{array}{l}\text { Soya lecithin } \\
\text { (mg) }\end{array}$ & $\begin{array}{l}\text { Surfactant concentration } \\
\text { (mg) }\end{array}$ & $\begin{array}{l}\text { Cholesterol } \\
\text { (mg) }\end{array}$ \\
\hline 1 & F (ACL) 1 & Span 60 & 10 & 468 & 468 & 52 \\
2 & F (ACL) 2 & Span 40 & 10 & 468 & 468 & 52 \\
3 & F (ACL) 3 & Span 20 & 10 & 468 & 468 & 52 \\
4 & F (ACL) 4 & Span 80 & 10 & 468 & 468 & 52 \\
\hline
\end{tabular}




\section{Entrapment efficiency}

Proniosomal formulations $(0.2 \mathrm{~g})$ after reconstitution with sufficient aqueous buffer (pH 7.4) in suitable centrifuge tube were executed for centrifugation using a cooling centrifuge at $3500 \mathrm{rpm}$ for about 1 $\mathrm{h}$ at $4^{\circ} \mathrm{C}[6]$. The clear and distinct supernatant was collected carefully to separate unentrapped ACL, and the sediment was then treated with ethanol $(1 \mathrm{ml})$ to lyse the vesicles and diluted with ethanol respectively, and absorbances were determined spectrophotometrically at $275 \mathrm{~nm}$. The entrapment efficiency was determined using the following equation,

$$
\% \text { E. E }=1-\frac{\text { ( Unentrapped drug) }}{(\text { Total drug })} \times 100
$$

\section{Optical microscopy}

The preparation with clear liquid crystalline state yielded niosomal suspension upon hydration; the same was mounted on a glass slide and examined for vesicles using a compound microscope under 100X magnification, magnified images were captured.

\section{In vitro diffusion}

In vitro release studies were performed for the preparations using Franz diffusion cell. Dialysis membrane was positioned between receptor and donor compartments. An equivalent dose of ACL preparation was introduced on the membrane. Receptor compartment was charged with pH 7.4 buffer $(15 \mathrm{ml})$. Cells were conditioned at $37 \pm 5^{\circ} \mathrm{C}$ with stirring at $500 \mathrm{rpm}$. At predetermined time periods aliquots were withdrawn from the receptor compartment, respectively and the same was replenished with fresh buffer. The samples were analysed spectrophotometrically.

\section{Preparation of aceclofenac proniosomal orabase}

Required equivalent quantities of gelatin, pectin, sodium carboxymethylcellulose, polyethylene glycol, and liquid paraffin were blended and triturated in optimum ratios for obtaining a smooth orabase in a mortar and pestle. Further desired amount of aceclofenac loaded proniosomal gel was incorporated with uniform stirring until homogeneity was achieved.

\section{Preparation of aceclofenac orabase}

Gelatin, pectin, sodium carboxymethylcellulose, polyethylene glycol, and liquid paraffin were blended and triturated in optimum ratios for obtaining orabase in a mortar and pestle. Further equivalent amount of ACL was incorporated with uniform stirring until homogeneity was achieved.

\section{In vitro release studies}

ACL proniosomal gel loaded orabase and drug orabase was characterized for its release employing membrane diffusion technique [7]. The preparation equivalent to $60 \mathrm{mg}$ aceclofenac was diluted with 1 $\mathrm{ml}$ of the buffer, introduced to the lower end of the glass cylinder on preconditioned dialysis membrane. The cylinder was maintained at 30 rpm with the membrane end being submerged in the dissolution jars. The dissolution medium phosphate buffer $\mathrm{pH} 7.4$ was maintained at $37 \pm 5^{\circ} \mathrm{C}$. The suitable volume of the sample was withdrawn at predetermined time periods; the same was replenished with fresh buffer and samples were assayed spectrophotometrically [8].

\section{Determination of mucoadhesive strength of the proniosomal orabase formulation}

The mucoadhesive strength of aceclofenac loaded proniosomal orabase formulation was determined by measuring the potency necessary for detaching the preparation from oral goat mucosa using dispensing balance [9]. Equal pieces $(2.5 \times 2.5 \mathrm{~cm})$, cut from the goat oral mucosal membranes, [10] were horizontally fixed to the upper stage of the dispensing balance keeping the mucosal side out. Proniosomal preparation $(0.5 \mathrm{~g})$ was positioned on the lower steel stage enabling the sample surface to adjoin mucosal membrane attached to the upper stage $[11,12]$. The sample was placed adjacent to the mucosal membrane for $5 \mathrm{~min}$. Into the other pan of dispensing balance water was added in dropwise manner until the mucosal membrane extricates from the gel sample. The mucoadhesive strength was measured in dyne $/ \mathrm{cm}^{2}$. The minimum amount of water required to detach the formulation from the oral mucosa surface was determined by using the following equation [13]

$$
\text { Detachment stress }=\mathrm{m} \times \frac{\mathrm{g}}{\mathrm{A}}
$$

Where $\mathrm{m}$ is the weight of water added to the balance in gram, $\mathrm{g}$ is acceleration due to gravity $\left(980 \mathrm{~cm} / \mathrm{s}^{2}\right)$, and $\mathrm{A}$ is an area of tissue exposed in $\mathrm{cm}^{2}$.

\section{Ex vivo permeation studies}

Proniosomal orabase permeation against buccal mucosa was determined employing altered Franz diffusion cell. The buccal mucosal membrane of goat pre-conditioned was placed in between donor and receptor compartments with the mucosal side facing the gel sample in the donor compartment. An equivalent amount of proniosomal orabase was introduced to the donor compartment, and subsequently, $50 \mathrm{ml}$ of phosphate buffer filled in the receptor compartment maintained at $37 \pm 5^{\circ} \mathrm{C}$ and stirred at $50 \mathrm{rpm}$. A suitable volume of sample was withdrawn at predetermined time periods, the same was replenished with fresh buffer and samples were assayed spectrophotometrically. The permeability coefficient calculated [14]

$$
\mathrm{K}_{\mathrm{p}}=\mathrm{J}_{\mathrm{ss}} / \mathrm{C}_{\mathrm{donar}}
$$

The flux of drug was calculated using $\mathrm{J}_{\mathrm{ss}}$ formula i.e.,

$$
\mathrm{J}_{\mathrm{ss}}=\text { amount of drug permeated } / \text { time } \times \text { area of membrane }
$$

The permeation coefficient of the drug was calculated using formula

$$
\mathrm{K}_{\mathrm{p}}=\text { flux } / \text { initial conc. of drug in donar chamber }
$$

\section{Determination of drug deposited into oral mucosa}

The amount of the aceclofenac retained in the buccal mucosa membrane was estimated by detaching the buccal mucosa membrane followed by diffusion studies rinsed with distilled water to washout formulation adhered to the membrane. The membrane was shredded into small pieces and then sonicated in $10 \mathrm{ml}$ ethanol for $30 \mathrm{~min}$ to leach out the drug. Then the sonicated ethanol was assayed spectrophotometrically for estimating the amount of ACL remained deposited in the buccal mucosa.

\section{Optical microscopy}

The proniosomal orabase and drug orabase was placed on a glass slide and observed for vesicles using a compound microscope under 100X magnification; magnified images were captured.

\section{Drug-excipient compatibility studies}

An efficient formulation emphasises on physiochemical and biological characteristics of active and excipient employed for product development. Hence signifies compatibility of active and excipients to yield the stable and safe product. Fourier transforms infrared spectroscopy is a significant analytical technique employed to study chemical interactions within active and excipients in the formulations. Active and excipient were mixed extensively with potassium bromide. The samples were introduced into diffuse reflectance sampler, and subsequent spectrums were recorded in wavelength region 4000-400 $\mathrm{cm}^{-1}$ in FT-IR.

\section{Scanning electron microscopy (SEM)}

The particle size of proniosomal orabase is a factor of prime importance. The surface morphology and size distribution of proniosomal orabase were studied by SEM. Proniosomal gel was applied on double-sided tape attached on aluminium stubs. The stubs were introduced to the vacuum chamber of SEM (XL 30 ESEM with EDAX, Philips, Netherlands). The samples were screened for morphological characteristics using a gaseous secondary electron detector (working pressure of 0.8 torr, acceleration voltage-30.00 KV) XL 30, (Philips, Netherlands) [15].

\section{RESULTS AND DISCUSSION}

To obtain appropriate vesicular formulation for delivery of ACL in the oral cavity for dental pain management, various proniosomal 
systems were formulated employing cholesterol and lecithin as membrane stabilizers along with a range of non-ionic surfactants, spans $(20,40,60$, and 80$)$ proniosomal gel systems were formulated for effective incorporation broad range of actives. Non-ionic surfactants employed non-toxic and compatible with the biological system. The systems were formulated by blending vesicular components with alcohol and aqueous phase yielding concentrated a liquid crystalline system that produces niosomal dispersion instantaneously on exposure to saliva in the oral cavity. Formulations pertaining to span 60 and 40 evinced semisolid consistency, whereas span 20 and 80 exhibited liquid consistency.

\section{Entrapment efficiency}

For a better pharmaceutical perspective, entrapment efficiency is a consequential parameter for collating various proniosomal formulations. ACL is incorporated into the vesicles. The Formulation comprising span 60 exhibited highest entrapment efficiency over other spans, span 80 showed minimal entrapment efficiency. Observed variation with entrapment efficiencies of different surfactants is the consequence of diverse structure and length of alkyl chain used as surfactants [16]. The entrapment efficiencies of the respective formulation are presented in (fig. 1).

\section{Optical microscopy}

The size of the formed vesicles has a major contribution towards in vivo fate. From (fig. 2) it is observed that the shape of proniosomal (F (ACL)1-F(ACL)4) formulations exhibited, following hydration yields niosomes with spherical morphology on $100 \mathrm{X}$ magnification.

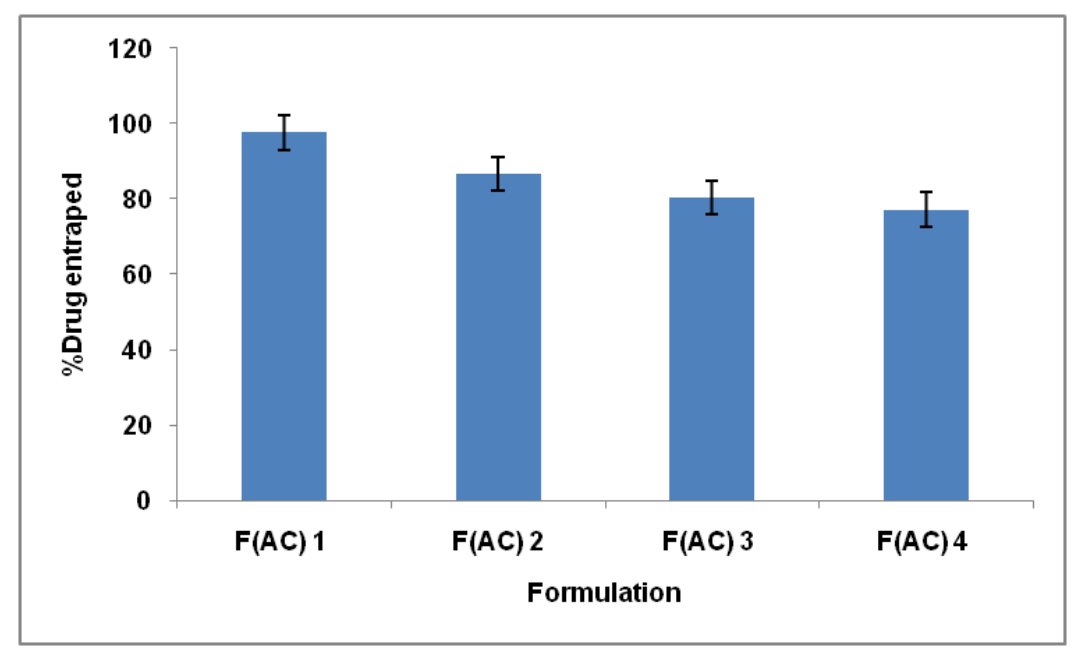

Fig. 1: Entrapment efficiency of formulated proniosomes mean \pm SD $(n=3)$
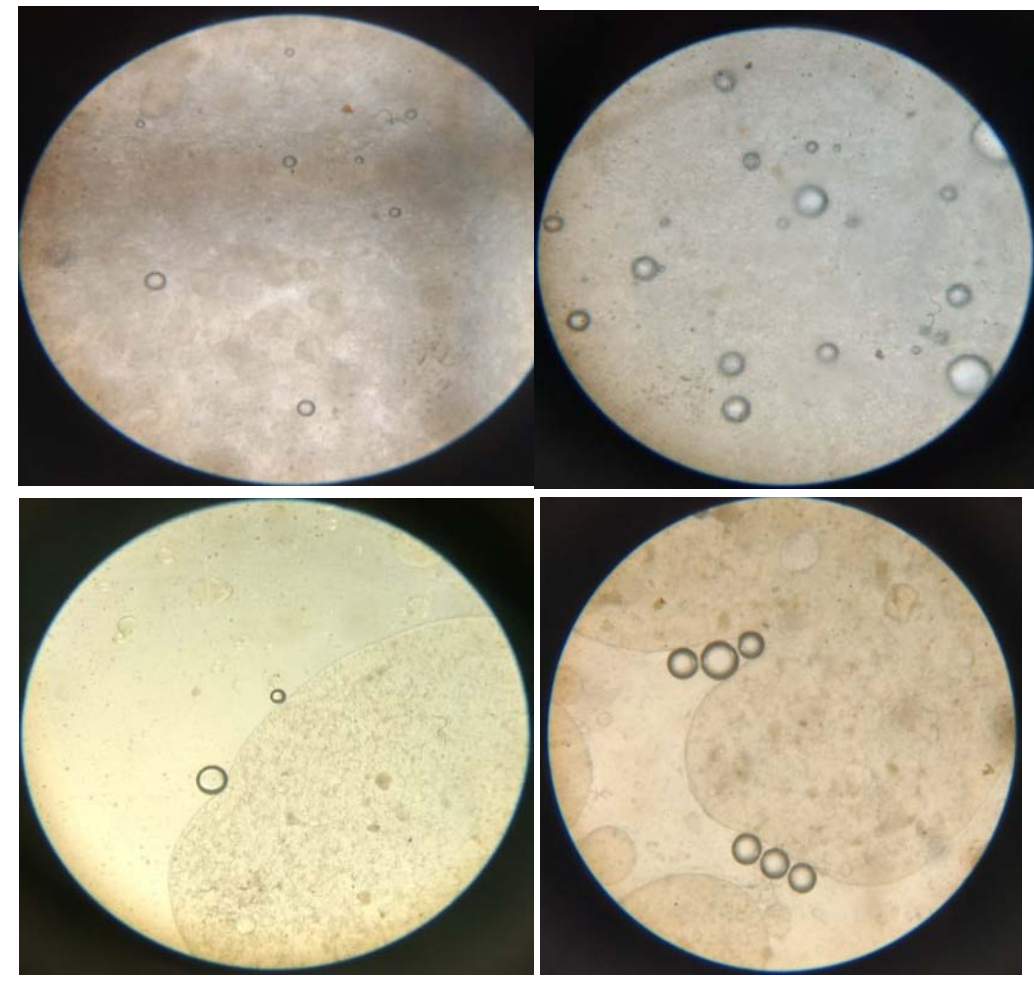

Fig. 2: Optical microscopic images of proniosomal formulations A) F1(Span60) B) F2(Span40) C) F3(Span20) D) F4(Span80) at 100X magnification 


\section{In vitro diffusion}

Amongst the different formulations, F(ACL)1 showed 45\% drug release for $24 \mathrm{~h}$ diffusion as shown (fig. 3). Consequently, formulation $F(A C L) 1$ exhibited higher diffusion as compared to F(ACL)2-F(ACL) 4 respectively. Commonly the release profiles of the proniosomal systems predominantly depended on hydrophobic lipophilic balance (HLB) value besides the alkyl chain length.

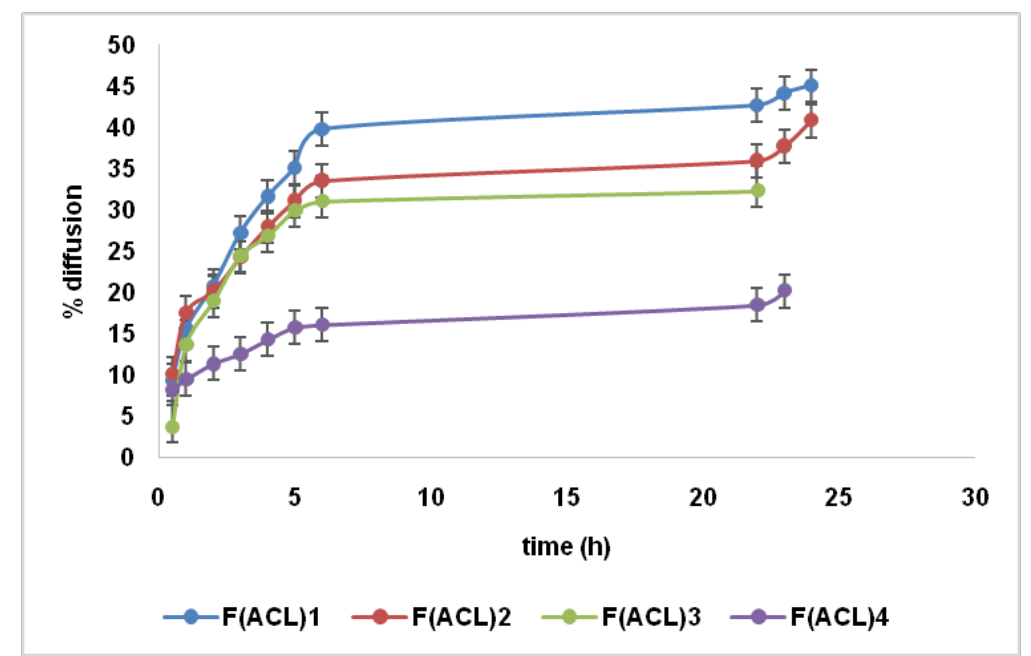

Fig. 3: In vitro diffusion profiles of proniosomal formulations data expressed $\operatorname{mean} \pm \operatorname{SD}(n=3)$

\section{Aceclofenac proniosomal orabase}

From the in vitro diffusion profile, with F(ACL)1 showing prominent profile compared to $\mathrm{F}(\mathrm{ACL}) 2-\mathrm{F}(\mathrm{ACL}) 4$ respectively, consequently F(ACL)1 was incorporated into orabase, enabling increased retention time within oral mucosa.

\section{Aceclofenac orabase}

ACL was directly incorporated into orabase as a control for comparison with the proniosomal orabase.

\section{In vitro release}

Release profiles comprehend the efficiency in the delivery of the drug by the proposed system. Complete release from ACL loaded orabase was achieved within $3 \mathrm{~h}$ which verify the aptitude of the drug to permeate through the membrane. It was learned the release of ACL proniosome system exhibited significantly lower release rates compared to control. This specifies that the lipid bilayer of niosomes limits drug release. An interrelation between the entrapment efficiency and the drug release was scrutinized. The higher proportion of drug entrapped within vesicles, the slower the release profile. The release from proniosomal orabase was slow and spread over more than $14 \mathrm{~h}$, compared to ACL orabase with a complete release within a few hours. Significantly the release of the proniosomal orabase formulation was protracted than that of ACL loaded orabase. The release profiles of proniosomal orabase and ACL loaded orabase are shown in (fig. 4).

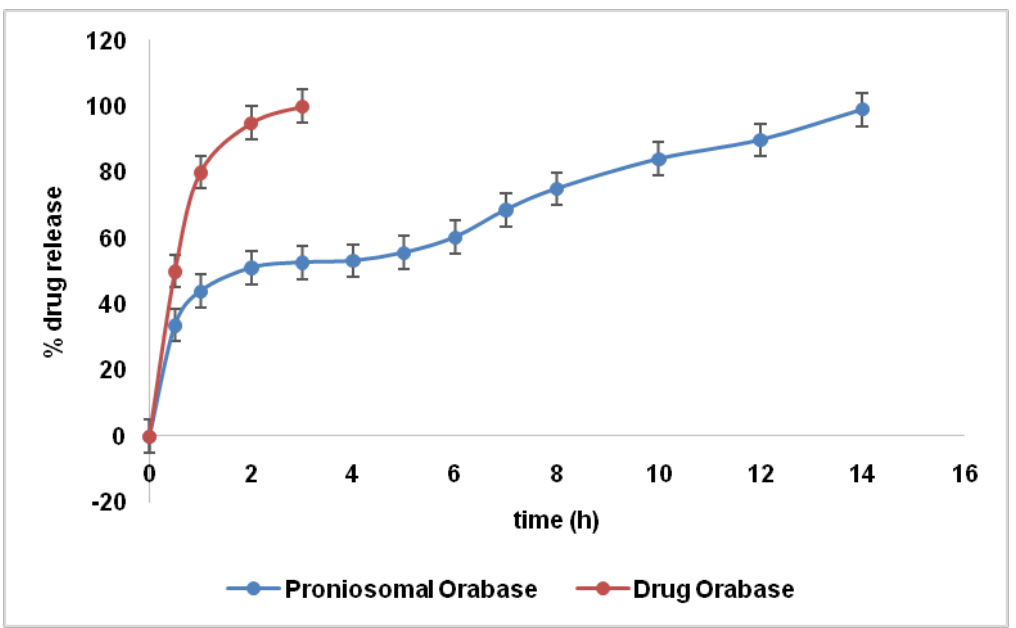

Fig. 4: In vitro release profiles of proniosomal and drug orabase data expressed mean $\pm \operatorname{SD}(n=3)$

\section{Mucoadhesive strength of the proniosomal orabase formulation}

For delivery of a therapeutic agent from the formulation system through oral mucosa should attribute simple application and sustained retention for establishing clinical efficiency. Even though proniosomal system features significant placement for oral mucosa, but the therapeutic effect is limited due to poor retention on the epithelium. To handle this impediment besides establishing better retention the 
formulation system was incorporated into the orabase mucoadhesive gel. Mucoadhesive strength can be related to fracture theory. The adhesive bond between systems is linked to the force needed to detach surfaces from each other. This theory is associated with the force essential for a polymer to separate from the mucus towards their adhesive bond strength. Consequently, the mucoadhesive strength in terms of detachment force of the system prepared by incorporating proniosomal gel in orabase and was examined. Proniosome incorporated orabase exhibited significantly increased in mucoadhesive force compared plain proniosome. Besides the weight applied to detach the mucous from the proniosomal gel mucoadhesive strength was found to be 6370 dynes $/ \mathrm{cm}^{2}$.

\section{Ex vivo permeation studies}

Post local administration in the oral cavity upon exposure to saliva, proniosomal gels transform into niosomal vesicles. Formed vesicles increase the penetration of stagnant drug molecules over the mucosal membrane. By adsorption and integration of intact vesicles with mucosal membrane enhances permeation of lipophilic molecules besides enhancing thermodynamic activity gradient at the membrane. From the release profiles (fig. 5) it was evident that after $24 \mathrm{~h}$ percentage drug released for proniosomal orabase and ACL loaded orabase were determined to be $36.6 \%$ and $21.6 \%$ respectively with permeation coefficient of $10.397 \mathrm{~cm}^{2} / \mathrm{h}$ and 3.270 $\mathrm{cm}^{2} / \mathrm{h}$. exhibited flux of $230 \mu \mathrm{g} / \mathrm{cm}^{2} / \mathrm{h}$ and $110 \mu \mathrm{g} / \mathrm{cm}^{2} / \mathrm{h}$ for proniosomal orabase and aceclofenac loaded orabase respectively. Comprehensively the permeation of ACL proniosomal orabase systems exhibited significantly enhanced and higher permeation compared to the control, recommending interaction of vesicles with mucosal membrane. The enhanced permeation of the prepared system is attributed to the existence of non-ionic surfactants besides formation of niosomal vesicles upon hydration.

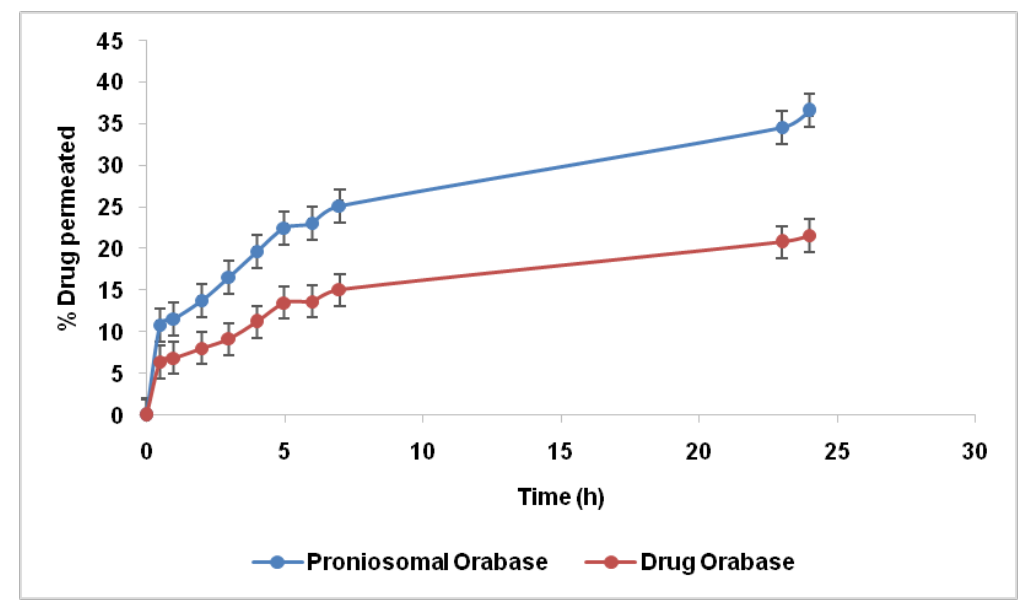

Fig. 5: Ex-vivo permeation profiles of proniosomal and drug orabase data expressed mean $\pm S D(n=3)$

\section{Drug deposited in oral mucosa}

Selected proniosomal orabase formulation exhibited 68.26\% retention in the oral mucosa. The formulation showed significant deposition within the oral mucosal layer when compared to control preparation. This reveals potential aspects of these intact niosomes to overcome the epithelial barrier of the oral mucosa and enhance concentrate within mucosal layers.

\section{Optical microscopy}

From (fig. 6) it is observed that the shape of proniosomal orabase formulation exhibited spherical morphology at 100X magnification.
The proniosomal orabase formulation system exhibited abundant vesicle formation in contrast to drug orabase.

\section{Drug-excipient compatibility studies}

FTIR studies were performed for ACL pure drug, proniosomal orabase and drug orabase and are in shown in (table 2). From the results, it was evident that there is no noticeable change in the peak of the spectrums of drug and excipients mixture. In recent observation there was no significant variation in dosage stability and used excipients was found. Individuality peaks of ACL were clearly established without any interaction of excipients used in proniosomal orabase formulation and drug orabase formulation as shown in the (fig. 7, 8, 9).

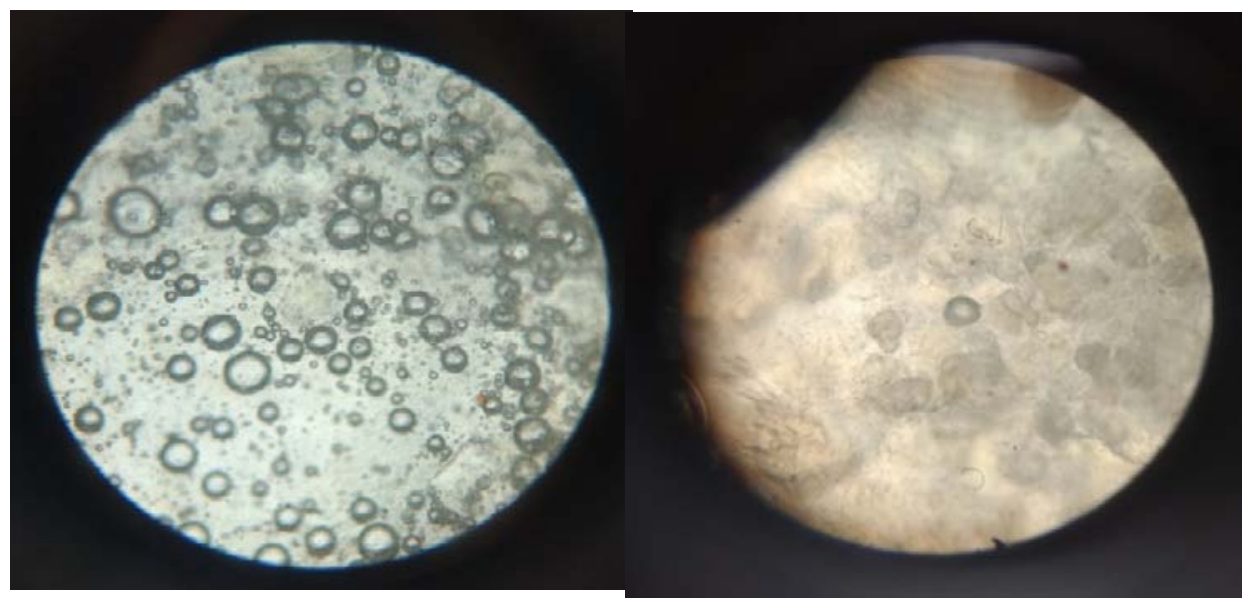

Fig. 6: Optical microscopic images of proniosomal and drug orabase formulations A) Proniosomal Orabase B) Drug orabase at 100X magnification 
Table 2: FTIR bands of aceclofenac, proniosomal orabase and drug orabase

\begin{tabular}{|c|c|c|c|}
\hline Functional group & IR band of ACL pure drug $\left(\mathrm{cm}^{-1}\right)$ & IR band of proniosomal orabase $\left(\mathrm{cm}^{-1}\right)$ & IR band of drug orabase $\left(\mathrm{cm}^{-1}\right)$ \\
\hline Alkane $\left(\mathrm{CH}_{2}-\mathrm{CH}_{2}\right)$ & 2934.54 & 2919.68 & 2919.60 \\
\hline Secondary Amine $(\mathrm{NH})$ & 661.97 & 615.31 & 682.14 \\
\hline Carboxylic Acid (COOH) & 1716.78 & 1712.70 & 1374.77 \\
\hline Ester (COOR) & 1770.13 & 1712.70 & 1748.19 \\
\hline Aromatic ring stretching $(\mathrm{C}=\mathrm{C}-\mathrm{C})$ & 1578.84 & 1459.43 & 1095.93 \\
\hline
\end{tabular}

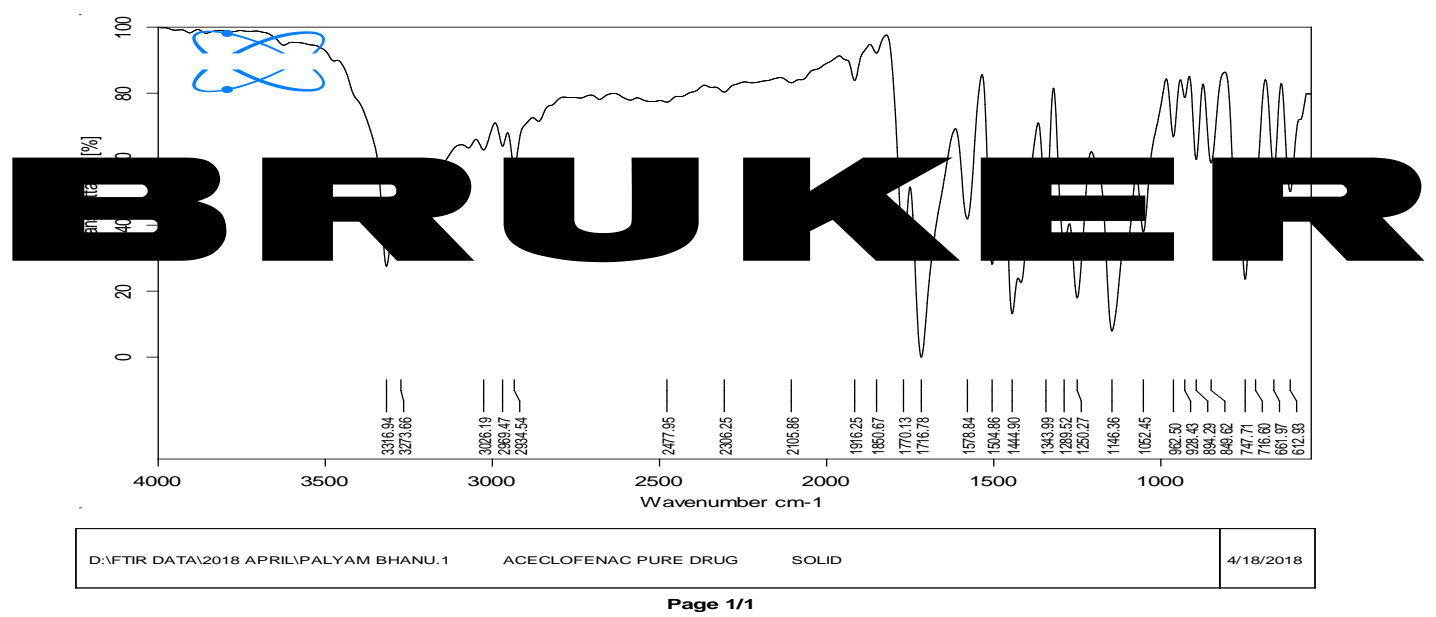

Fig. 7: FTIR Aceclofenac pure drug

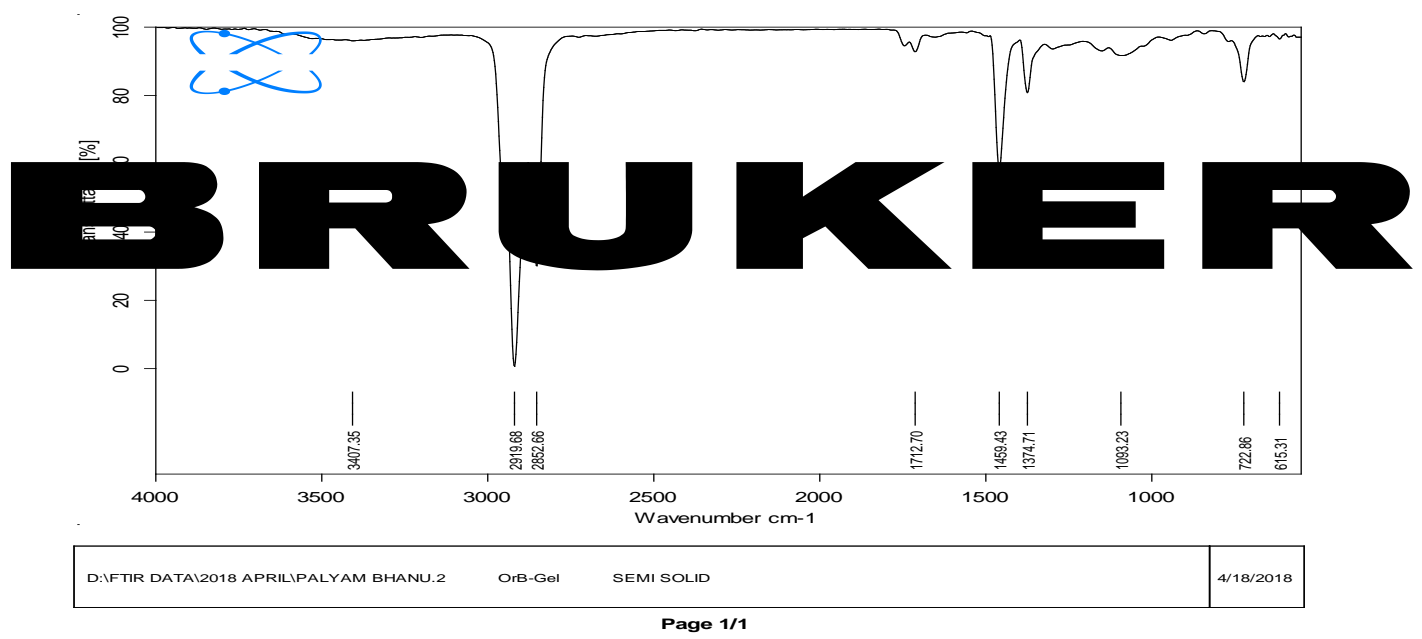

Fig. 8: FTIR Proniosomal orabase

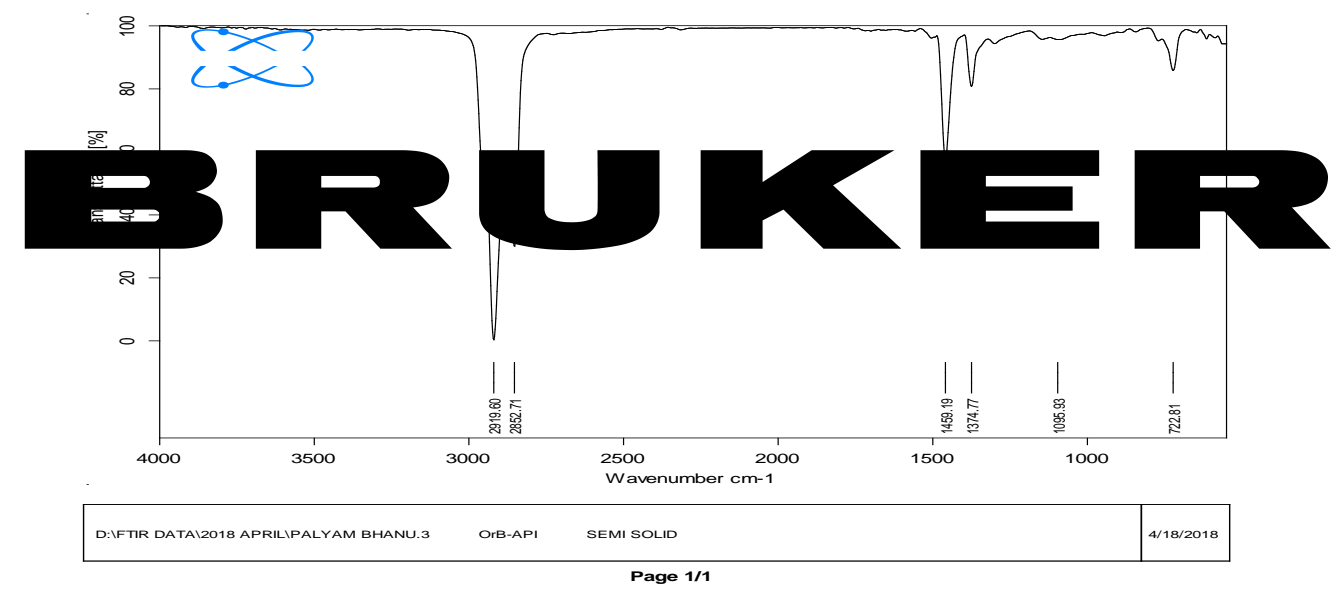

Fig. 9: FTIR drug orabase 


\section{Scanning electron microscopy (SEM)}

As depicted in the SEM images revealed the well identified spherical morphology of proniosomal orabase, post hydration prepared employing span 60 , increased vesicle size greatly lowers mucosal penetration. Considering the aforementioned size distribution was examined, and the formulation exhibited particle size ranges from 136 $\mu \mathrm{m}$ to $236 \mu \mathrm{m}$ as shown in (fig. 10) conferring enhanced mucosal penetration.

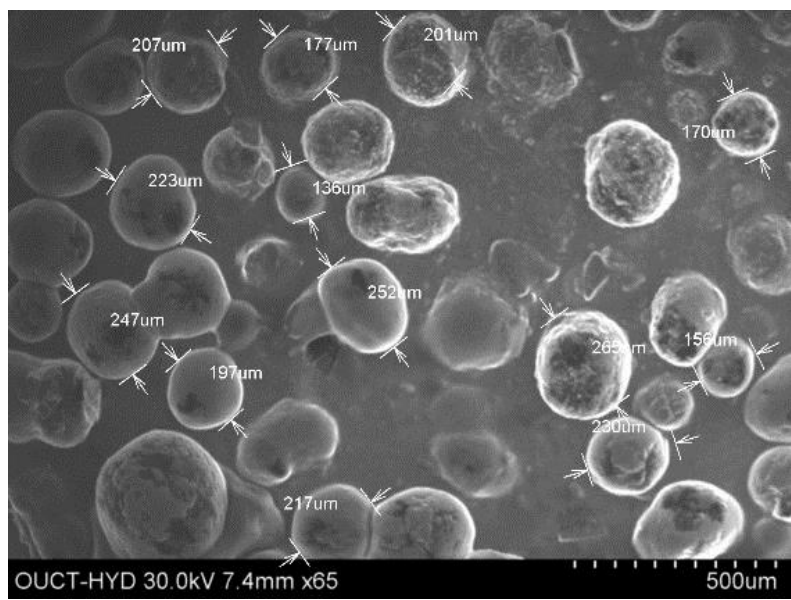

Fig. 10: SEM image of proniosomal orabase

\section{CONCLUSION}

There have been enormous efforts put in the development of novel routes for NSAIDs administration to deliver adaptive treatments for patients ailing with dental pain with better safety margin without losing the efficiency for analgesia and pain management.

Endeavouring effort was made in preparing much safer and an alternative for oral route. Considering proniosomal gels in which aceclofenac was successfully entrapped with high efficiency into vesicles. Proniosomal gel formulation F(ACL)1, considered optimal formulation with $\mathrm{EE} \%(97.60 \pm 1.85 \%)$ post reconstitution. As a result, the optimal formula was further incorporated into orabase with desirable mucoadhesive behaviour essential to achieve increased retention for effective pain management. The formula exhibited significant permeation with two-fold increased flux and sustained for longer periods compared to the aceclofenac control at the same dose level. Hence, orabase loaded with proniosomal gels may be a promising carrier for NSAIDs in dental pain management with their intact vesicles and safety aspects for local action for longer periods with simple preparation technique.

\section{ACKNOWLEDGMENT}

The authors are grateful to GITAM Institute of Pharmacy, GITAM (Deemed to be University), Visakhapatnam for providing necessary facilities and support.

\section{AUTHORS CONTRIBUTIONS}

All the author have contributed equally

\section{CONFLICT OF INTERESTS}

All authors have none to declare

\section{REFERENCES}

1. May N, Epstein J, Osborne B. Selective COX-2 inhibitors: a review of their therapeutic potential and safety in dentistry. Oral Surg Oral Med Oral Pathol Oral Radiol Endod 2001;92:399-400.

2. Liliana L Jorge, Caroline C Feres, Vitor EP Teles. Topical preparations for pain relief: efficacy and patient adherence. J Pain Res 2011;4:11-24.

3. Shukla ND, Tiwari M. Proniosomal drug delivery systems: clinical applications. Int J Res Pharm Biomed Sci 2011;2:880-7.

4. Fang JY, Yu SY, Wu PC, Huang YB, Tsai YH. In vitro skin permeation of estradiol from various proniosome formulations. Int J Pharm 2001;215:91-9.

5. Alam MI, Baboota S, Kohli K, Ali J, Ahuja A. Pharmacodynamic evaluation of proniosomal transdermal therapeutic gel containing celecoxib. Scienceasia 2010;36:305-11.

6. Mokhtar M, Sammour OA, Hammad MA, Megrab NA. Impact of some formulation parameters on flurbiprofen encapsulation and release rates of niosomes from proniosomes. AAPS PharmSciTech 2008;9:782-90.

7. Devaraj GN, Parakh SR, Devraj R, Apte SS, Rao BR, Rambhau D. Release studies on niosomes containing fatty alcohols as bilayer stabilizers instead of cholesterol. J Colloid Interface Sci 2002;251:360-5.

8. Hanan Jalal Kassab, Lena Murad Thomas, Saba Abdulhadi Jabir. Development and physical characterization of a periodontal bioadhesive gel of gatifloxacin. Int J Appl Pharm 2017;9:31-6.

9. Choi HG, Jung JH, Ryu JM, Yoon SJ, Oh YK, Kim CK. Development of in situ gelling and mucoadhesive acetaminophen liquid suppository. Int J Pharm 1998;165:33-6.

10. Sezer AD, Cevher E, Hatipoglu F, Ogurtan Z, Bas AL, Akbuga J. The use of fucosphere in the treatment of dermal burns in rabbits. Eur J Pharm Biopharm 2008;69:189-98.

11. Bonacucina G, Martelli S, Palmieri GF. Rheological, mucoadhesive and release properties of Carbopol gels in hydrophilic cosolvents. Int J Pharm 2004;282:115-30.

12. Lalit Kumar, Ruchi Verma. Chemical stability studies of bioadhesive topical gel. Int J Pharm Pharm Sci 2011;3:101-4.

13. Ali J, Khar R, Ahuja A, Kalra R. Buccoadhesive erodible disk for treatment of oro-dental infections: design and characterisation. Int J Pharm 2002;238:93-103.

14. Thakur R, Anwer Md K, Shams MS, Ali A, Khar RK, Shakeel F, et al. Proniosomal transdermal therapeutic system oflosartan potassium: development and pharmacokinetic evaluation. J Drug Targeting 2009;17:442-9.

15. Ankit Acharya, Kiran Kumar GB, Mohammed Gulzar Ahmed, Saroj Paudel. A novel approach to increase the bioavailability of candesartan cilexetil by proniosomal gel formulation: in vitro and in vivo evaluation. Int J Pharm Pharm Sci 2016;8:241-6

16. Hao Y, Zhao F, Li N, Yang Y, Li K. Studies on a high encapsulation of colchicine by a niosome system. Int J Pharm 2002;224:73-80. 